\title{
Roles of the Pectoral Musculoskeletal Framework and the Pericardium in Cardiac Function in Carp
}

\author{
Takao Shima and Kenji Namba \\ Faculty of Applied Biological Science, Hiroshima University, Higashi-Hiroshima, \\ Hiroshima 739, Japan
}

(Received December 25, 1995)

\begin{abstract}
In situ perfused hearts of carp were used to investigate the roles of the pectoral musculoskeletal framework covering the pericardial cavity, and the pericardium in cardiac performance. Removing the pectoral musculoskeletal framework decreased stroke volume and cardiac output to about $70 \%$ and $67 \%$ of the initial condition, respectively, and raised atrial filling pressure from $-2.9 \pm 0.48 \mathrm{mmH}_{2} \mathrm{O}$ to above ambient levels. Cutting the pericardium, however, caused no further significant changes in cardiac parameters. Thus, the pectoral musculoskeletal framework of carp is a significant component of the atrial filling via the vis-ä-fronte mechanism. On the other hand, the ability of the heart to undertake pressure-related work was significantly enhanced by both removing the pectoral musculoskeletal framework and cutting the pericardium. These results show that both the pectoral musculoskeletal framework and the pericardium prevent the cardiac chambers from over-distention and excessive pressure-related work.
\end{abstract}

Key words: carp, cardiovascular function, musculoskeletal framework, pericardium, atrial filling, vis-ä-fronte filling, in situ perfused heart

In some species of fish, the pericardial cavity is essential for atrial filling via the $v i s-\grave{a}$-fronte mechanism (suction filling), since ejection of blood from the ventricle renders intrapericardial pressure subambient and distends the atrial chamber. Blood flow into the atrium from the sinus venosus is thus enhanced. ${ }^{1,2)}$ Owing to vis-à-fronte filling, central venous blood pressure becomes subambient. ${ }^{2,3}$,

In situ perfused hearts of active teleosts such as rainbow trout $^{4)}$ and yellowfin tuna ${ }^{5)}$ and elasmobranchs such as dogfish ${ }^{6}$ maintain physiological cardiac output by $v i s-\dot{a}$ fronte atrial filling. In contrast, perfused hearts of benthic teleosts such as ocean pout, ${ }^{7}$ sea raven, ${ }^{8)}$ and eel ${ }^{9)}$ require positive venous pressures (vis-ä-tergo filling) to maintain physiological stroke volume. A rigid pericardial cavity made of a rigid pericardium (elasmobranchs) or a rigid musculoskeletal framework to which a relatively thin pericardium is attached (active teleosts) may be required for the vis-áa-fronte filling mechanism, ${ }^{2)}$ since cutting the pericardium of in situ perfused hearts of $\operatorname{dogfish}^{6)}$ and trout $^{4)}$ decreased stroke volume. The pericardium in fish may also serve to prevent over-distention of the cardiac chambers. ${ }^{4,9)}$

The roles of the pericardium of teleosts have been investigated, while little attention has been paid to the roles of the musculoskeletal framework surrounding the pericardial cavity in cardiac function. Moreover, little information is available on the roles of the pericardium of fish with a sac-like ventricle, although this type of the ventricle predominates among fish. ${ }^{10}$

This study was conducted to determine (1) the roles of the pectoral musculoskeletal framework, and (2) the roles of the pericardium in atrial filling and cardiac performance in carp that have a sac-like ventricle.

\section{Materials and Methods}

\section{Animal}

Carp Cyprinus carpio, (body mass $=481 \pm 10.1 \mathrm{~g}$; $\mathrm{n}=20$ ) were obtained from a commercial hatchery and maintained in an outdoor $1000 l$ tank with circulating water at ambient temperature and photoperiod. Prior to the experiments, the fish were transferred to an indoor 500 $l$ tank and acclimated to $25^{\circ} \mathrm{C}$ for at least two weeks. They were fed commercial carp pellets daily to satiation but fasted for $24 \mathrm{~h}$ before use.

\section{Heart Preparation}

The method of in situ perfused heart preparation was essentially identical to the method of Farrell et al. ${ }^{5)}$ The fish were anesthetized in $0.1 \mathrm{~g} / \mathrm{l}$ MS-222 solution buffered with $\mathrm{NaHCO}_{3}$, and were killed by a sharp blow to the head. The trunk of each fish was transected at the pelvic fins. The skull was opened, and the heart was denervated by galvanocaustic amputation of the brain. An input cannula (stainless steel, $1.85 \mathrm{~mm}$ in outer diameter) was immediately inserted into the sinus venosus via the right hepatic vein followed by saline perfusion. Then, an input pressure sensing cannula (stainless steel, $1.85 \mathrm{~mm}$ in outer diameter) was inserted into the sinus venosus via the left hepatic vein. The ventral aorta was exposed, and cannulated with an output cannula in which the pressure sensing cannula was implanted. Each cannula was secured to the vessel with silicon tubing $1 \mathrm{~mm}$ in outer diameter. The severed posterior cardinal veins in the kidney were sealed with a surgical adhesive (Aron Alpha A: Toagosei), although no detectable loss of perfusate from the common cardinal veins was observed during perfusate recirculation for at 
least 120 min under experimental input pressures. Bipolar E.C.G. electrodes were inserted into the pectoral musculoskeletal framework from the joint of the pelvic fins so as to locate the tips of the electrodes on both sides of the ventricle. The in situ heart preparation was completely immersed in a saline-filled organ bath with a water jacket to maintain the experimental temperature at $25^{\circ} \mathrm{C}$. The input cannula was connected to an input constant pressure device. ${ }^{11)}$ The output cannula was joined to an output pressure head via a saline-filled tubing (Fig. 1).

Atrial filling and output pressure were varied by adjusting the heights of the input constant pressure device and the output pressure head, respectively. The input and output pressure sensing cannulae were connected to pressure transducers (Spectramed DX 280: Nihon Kohden) via saline-filled tubings. These cannulae were used to measure atrial filling and output pressures directly without any need to correct cannula resistances. $\left.{ }^{9}\right)$

Prior to experiments, each heart was left in the organ bath for $10-15 \mathrm{~min}$. Surface level of saline in the organ bath was referred to as $0 \mathrm{mmH}_{2} \mathrm{O}$ for pressure measurements. Pressure and ECG signals were amplified, recorded on a chart recorder (AP621G-RM6100: Nihon Kohden) and input to a personal computer via an analog-digital interface (Mac lab/8: AD instrument) for analysis.

Perfusate composition was $105 \mathrm{~mm} \mathrm{NaCl} ; 5 \mathrm{mM} \mathrm{KCl} ; 1$ $\mathrm{mM} \mathrm{MgSO}_{4} \cdot 7 \mathrm{H}_{2} \mathrm{O} ; 2.5 \mathrm{mM} \mathrm{CaCl}_{2} ; 2.3 \mathrm{mM} \mathrm{Na}_{2} \mathrm{HPO}_{4}$; $0.46 \mathrm{mM} \mathrm{NaH}_{2} \mathrm{PO}_{4} \cdot 2 \mathrm{H}_{2} \mathrm{O}$, and $5.5 \mathrm{~mm}$ glucose. The perfusate was gassed with $5 \% \mathrm{CO}_{2}$ and $95 \% \mathrm{O}_{2}$ and $\mathrm{pH}$ was adjusted to $7.73\left(25^{\circ} \mathrm{C}\right.$ ) with $\mathrm{NaHCO}_{3}$ (approximately $2.5 \mathrm{~g}$ / l). The perfusate was kept at $25^{\circ} \mathrm{C}$.

\section{Protocols}

Effects of Removing Pectoral Musculoskeletal Framework and Cutting Pericardium on Atrial Filling

Stroke volume was varied by adjusting input pressures so that cardiac output was set at $15 \mathrm{~m} / / \mathrm{min} \cdot \mathrm{kg}$ body mass (B.M.) against an output pressure of $30 \mathrm{cmH}_{2} \mathrm{O}$ while the heart had a steady intrinsic rhythm. The heights of the input pressure device and output pressure head were kept constant throughout the study. After all cardiac data were

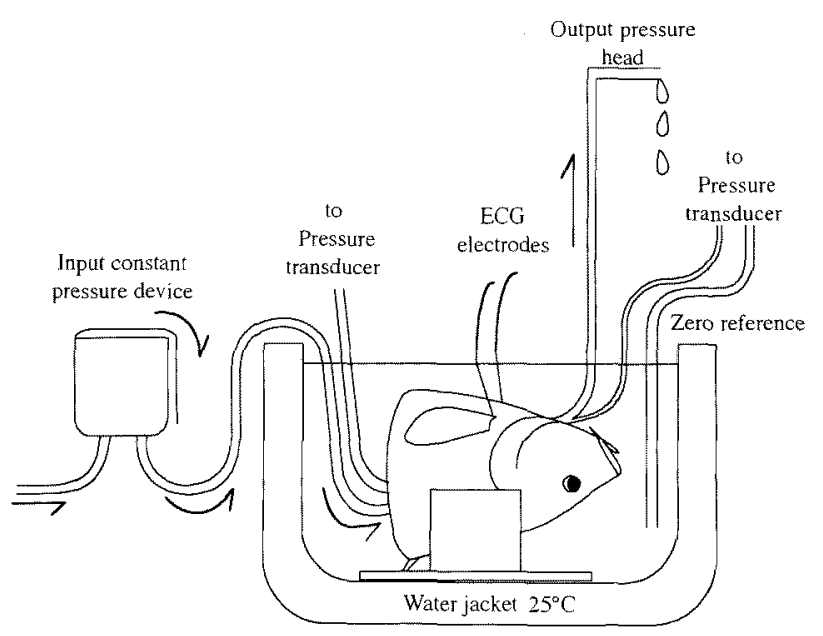

Fig. 1. A schernatic diagram of the experimental set up.

The heights of the input pressure device and/or output pressure head were altered to set the cardiac output. recorded for an intact perfused heart, the pectoral musculoskeletal framework was removed by dissecting the right cleithrum, pectoral fin, and surrounding muscle. After recording all cardiac data, the pericardium was cut to expose the cardiac chambers so that movement of the cardiac chambers would not be obstructed by the pericardial wall. Cardiac performance was again recorded after these perturbations.

\section{Effects of Removing Pectoral Musculoskeletal Framework and Cutting Pericardium on Pressure-related Work}

Cardiac output was repeatedly set at about 15 $\mathrm{ml} / \mathrm{min} \cdot \mathrm{kg} \mathrm{B.M}$. against an output pressure of $40 \mathrm{cmH}_{2} \mathrm{O}$ under three different conditions: with the pectoral musculoskeletal framework intact, with the pectoral musculoskeletal framework removed (but the pericardium intact), and with the pericardium cut. The output pressure was altered in a stepwise fashion $\left(25,40,50 \mathrm{cmH}_{2} \mathrm{O}\right)$ under these conditions without changing the height of the input pressure device. Cardiac data were obtained as above.

\section{Calculations}

Heart rate (beats $/ \mathrm{min}$ ) was determined from $E C G$, and cardiac output from the weight of the perfusate discharged through the output cannula for one minute. Stroke volume was calculated as [cardiac output $(\mathrm{m} / / \mathrm{min})] /$ [heart rate (beats/min)]. Cardiac output and stroke volume were then normalized per $\mathrm{kg}$ body mass (B.M.). Power output of the heart ( $\mathrm{mW} / \mathrm{g}$ ventricular mass) was calculated from [(cardiac output/60) $\times$ (output pressure - sinus venosus pressure) $/($ ventricular mass)] $\times 0.098$. The wet weight of the fish was measured before the experiment. The wet weight of the ventricle $(0.397 \pm 0.0170 \mathrm{~g}$, $\mathrm{n}=20)$ and the bulbus arteriosus $(0.254 \pm 0.0173 \mathrm{~g}, \mathrm{n}=20)$ was determined afterward.

\section{Statistics}

Results were expressed as means \pm 1 S.E.M. Statistical significance of differences was assessed using one-way ANOVA followed by Fisher's PLSD for pairwise comparison.

\section{Atrial Filling \\ When the pectoral musculoskeletal framework was in-} tact, in situ perfused carp heart pumped a cardiac output of $14.7 \pm 0.3 \mathrm{ml} / \mathrm{min} \cdot \mathrm{kg}$ B.M. at a mean atrial filling pressure of $-2.9 \pm 0.48 \mathrm{mmH}_{2} \mathrm{O}$ against an output pressure of $30 \mathrm{cmH}_{2} \mathrm{O}$ (Table 1). Heart rate was $70 \pm 3.4$ beats $/ \mathrm{min}$. Removing the pectoral musculoskeletal framework and cutting the pericardium had no effect on heart rate. However, removing the pectoral musculoskeletal framework decreased stroke volume to about $70 \%$, cardiac output to about $67 \%$, and power output to about $66 \%$ of the control levels, and increased atrial filling pressure to above ambient. Cutting the pericardium caused no further significant changes in cardiac parameters (Table 1, Fig. 2).

\section{Pressure-related Work}

No major changes in heart rate occurred by increasing the output pressure or removing the pectoral mus- 
Table 1. Cardiac variables in in situ perfused carp heart before and after the pectoral musculoskeletal framework was removed, and when the pericardium was cut $(n=10)$

\begin{tabular}{|c|c|c|c|}
\hline & $\begin{array}{l}\text { Pectoral musculoskelctal } \\
\text { framework intact }\end{array}$ & $\begin{array}{l}\text { Pectoral musculoskeletal } \\
\text { framework removed }\end{array}$ & $\begin{array}{c}\text { Pericardium } \\
\text { cut }\end{array}$ \\
\hline Heart rate (beats/min) & 70 & 70 & 70 \\
\hline S.E.M. & \pm 3.4 & \pm 3.5 & \pm 3.6 \\
\hline Cardiac output $(\mathrm{m} / / \mathrm{min} \cdot \mathrm{kg} \mathrm{b} . \mathrm{m})$. & 14.66 & $9.87^{*}$ & $10.05^{*}$ \\
\hline S.E.M. & \pm 0.295 & \pm 0.597 & \pm 0.683 \\
\hline Stroke volume $(\mathrm{m} l / \mathrm{kg} \mathrm{b.m.)}$ & 0.21 & $0.15^{*}$ & $0.15^{*}$ \\
\hline S.E.M. & \pm 0.011 & \pm 0.014 & \pm 0.015 \\
\hline Power output (mW/g v.m.) & 0.97 & $0.64 *$ & $0.64^{*}$ \\
\hline S.E.M. & \pm 0.063 & \pm 0.054 & \pm 0.062 \\
\hline Atrial filling pressure $\left(\mathrm{mmH}_{2} \mathrm{O}\right)$ & -2.9 & $1.0^{*}$ & $1.3^{*}$ \\
\hline S.E.M. & \pm 0.48 & \pm 0.58 & \pm 0.47 \\
\hline
\end{tabular}

* Significantly different from the values of the ventral musculoskeletal framework intact $(P<0.05)$.

b.m. body mass, v.m. ventricular mass.

Table 2. Effect of output pressure on in situ perfused carp heart before and after pectoral musculoskeletal framework was removed, and when the pericardium was cut $(n=10)$

\begin{tabular}{|c|c|c|c|c|c|c|c|c|c|}
\hline \multirow{2}{*}{ Output pressure $\left(\mathrm{cmH}_{2} \mathrm{O}\right)$} & \multicolumn{3}{|c|}{$\begin{array}{l}\text { Pectotral musculoskeletal } \\
\text { framework intact }\end{array}$} & \multicolumn{3}{|c|}{$\begin{array}{l}\text { Pectotral musculoskeletal } \\
\text { framework removed }\end{array}$} & \multicolumn{3}{|c|}{$\begin{array}{l}\text { Pereardium } \\
\text { cut }\end{array}$} \\
\hline & 25 & 40 & 50 & 25 & 40 & 50 & 25 & 40 & 50 \\
\hline Heart rate (beats/min) & 70 & 70 & 68 & 67 & 66 & 66 & 69 & 67 & 69 \\
\hline S.E.M. & \pm 2.0 & \pm 2.1 & \pm 2.5 & \pm 2.6 & \pm 2.6 & \pm 2.6 & \pm 2.2 & \pm 2.2 & \pm 2.2 \\
\hline Cardiac output ( $\mathrm{m} / / \mathrm{min} \cdot \mathrm{kg}$ b.m.) & $19.34^{*}$ & 14.86 & $9.13^{*}$ & $16.50^{+}$ & 15.05 & $11.96^{* \dagger}$ & $15.48^{\dagger}$ & 14.81 & $13.64^{* \dagger}$ \\
\hline S.E.M. & \pm 0.841 & \pm 0.175 & \pm 0.919 & \pm 0.500 & \pm 0.223 & \pm 0.855 & \pm 0.213 & \pm 0.225 & \pm 0.493 \\
\hline S.E.M. & \pm 0.017 & \pm 0.006 & \pm 0.013 & \pm 0.014 & \pm 0.012 & \pm 0.013 & \pm 0.010 & \pm 0.010 & \pm 0.011 \\
\hline Power output (mW/g v.m.) & 1.24 & 1.38 & $1.04^{*}$ & $1.02^{*}$ & 1.38 & $1.34^{\dagger}$ & $0.95^{*}$ & 1.37 & $1.55^{* \dagger}$ \\
\hline S.E.M. & \pm 0.055 & \pm 0.033 & \pm 0.105 & \pm 0.051 & \pm 0.035 & \pm 0.078 & \pm 0.032 & \pm 0.037 & \pm 0.043 \\
\hline Atrial filling pressure $\left(\mathrm{mmH}_{2} \mathrm{O}\right)$ & $-6.3^{*}$ & -1.3 & $1.8^{*}$ & 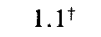 & $2.0^{\dagger}$ & $3.8^{\dagger}$ & $0.8^{\dagger}$ & $1.2^{\dagger}$ & 1.8 \\
\hline S.E.M. & \pm 0.79 & \pm 0.68 & \pm 0.71 & \pm 0.42 & \pm 0.59 & \pm 0.85 & \pm 0.34 & \pm 0.32 & \pm 0.42 \\
\hline
\end{tabular}

* Significantly different from the values against the output pressure of $40 \mathrm{cmH}_{2} \mathrm{O}$ under each conditions $(P<0.05)$.

† Significantly different from the values of the pectoral musculoskeletal framework intact against the same output pressures $(P<0.05)$

b.m. body mass, v.m. ventricular mass.

culoskeletal framework or cutting the pericardium (Table 2). When the pectoral musculoskeletal framework was intact, changing the output pressure stepwise from 25 to 40 $\mathrm{cmH}_{2} \mathrm{O}$ significantly decreased stroke volume by about $20 \%$ and cardiac output by about $23 \%$, and increased atrial filling pressures from $-6.3 \pm 0.79$ to $-1.3 \pm 0.68$ $\mathrm{mmH}_{2} \mathrm{O}$. Raising output pressure to $50 \mathrm{cmH}_{2} \mathrm{O}$ significantly decreased cardiac output and power output due to the further decrease in stroke volume. The atrial filling pressure became positive (Table 2).

When the pectoral musculoskeletal framework was re-

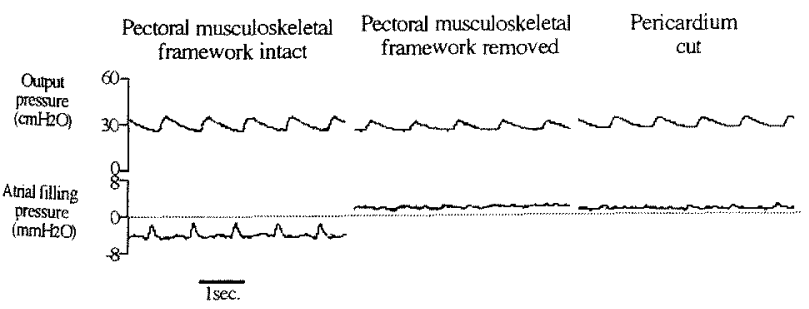

Fig. 2. Simultaneously recorded output pressure and atrial filling pressure from an in situ perfused carp heart before and after the pectoral musculoskeletal framework was removed, and when the pericardium was cut. moved, a positive atrial filling pressure was needed to generate a cardiac output of $15 \mathrm{ml} / \mathrm{min} \cdot \mathrm{kg} \mathrm{B}$.M. against an output pressure of $40 \mathrm{cmH}_{2} \mathrm{O}$. Stroke volume and atrial filling pressure did not change significantly when the output pressure was raised from 25 to $40 \mathrm{cmH}_{2} \mathrm{O}$. Raising the output pressure to $50 \mathrm{cmH}_{2} \mathrm{O}$ resulted in significant decreases in stroke volume and cardiac output (Table 2).

When the pericardium was cut, stroke volume and atrial filling pressure at output pressures of 25 and $40 \mathrm{~cm} \mathrm{H}_{2} \mathrm{O}$ did not significantly differ from those obtained before cutting. Raising the output pressure to $50 \mathrm{cmH}_{2} \mathrm{O}$ significantly increased cardiac power output since the decrease in stroke volume was small (Table 2).

\section{Discussion}

In situ perfused carp hearts within the intact pectoral musculoskeletal framework were capable of pumping a cardiac output of $15 \mathrm{ml} / \mathrm{min} \cdot \mathrm{kg} \mathrm{B}$.M. at a subambient atrial filling pressure against an output pressure of $30 \mathrm{cmH}_{2} \mathrm{O}$. Thus, in situ perfused carp hearts with the sac-like ventricle maintained physiological cardiac output by vis-àfronte atrial filling.

Removing the pectoral musculoskeletal framework increased atrial filling pressure to above ambient levels, and 
decreased stroke volume to about $70 \%$ of the initial condition, although the pericardial cavity remained intact. Moreover, cutting the pericardium caused no further significant changes in stroke volume, atrial filling pressure, cardiac output, and power output. On the other hand, cutting the pericardium of in situ perfused hearts at rest reduced stroke volume to $55 \%$ in rainbow trout ${ }^{4)}$ and $45 \%$ in dogfish. ${ }^{6}$ These functional differences probably resulted from the species-specific anatomical arrangements of the pectoral musculoskeletal framework and the pericardium. Thus, in carp, it is not the pericardium itself but the pectoral musculoskeletal framework that is essential for $v i s-\vec{a}$ fronte atrial filling.

In situ perfused hearts usually maintain cardiac outputs when the output pressure is altered within the physiological range (homeometric regulation). ${ }^{2)}$ The highest output pressure used in this study was almost comparable to the end-systolic pressure in the bulbus arteriosus in resting carp $\left(44 \mathrm{cmH}_{2} \mathrm{O}\right)$. In spite of this, the stroke volume of the perfused carp heart, when the pectoral musculoskeletal framework was intact, decreased by $50 \%$ as the output pressure was raised from 25 to $50 \mathrm{cmH}_{2} \mathrm{O}$ (Table 2). In contrast, stroke volume was highly stable after cutting the pericardium. Clearly, carp heart was unable to show homeometric regulation at least in situ, when confined within the intact pericardial cavity.

Stroke volume in an in situ perfused trout heart during increasing output pressure is maintained by increases in both end-diastolic and end-systolic volumes of the ventricle, but decreases at an extremely high output pressure, since end-systolic volume increases further while end-diastolic volume becomes maximum. ${ }^{13)}$ On the other hand, Franklin and Davie ${ }^{\text {) }}$ found opening the pericardium in eel to result in significantly decreased maximum sustainable output pressure.

The bulbus arteriosus of carp is very distensible for the pressure range from 7.3 to $33 \mathrm{mmHg}$ (approximately 10 to $\left.45 \mathrm{cmH}_{2} \mathrm{O}\right),{ }^{14)}$ and has a relatively large volume $(66 \pm 2.2 \%$ of ventricle mass in this study). Increases in the volume of the bulbus arteriosus by increased output pressures within a finite volume of the pericardial cavity may restrict atrial and ventricular end-diastolic volumes, the latter being the primary determinant of the stroke volume. ${ }^{3,15)}$ Thus, in carp, the pectoral musculoskeletal framework and the pericardium, and presumably the bulbus arteriosus, may serve to prevent the heart from undertaking high pressurerelated work.

\section{References}

1) A. P. Farrell: From Hagfish to Tuna: A perspective on cardiac function in fish. Physiol. Zool., 64, 1137-1164 (1991).

2) A. P. Farrell and D. R. Jones: The heart, in "Fish Physiology" (ed. by W. S. Hoar, D. J. Randall, and A. P. Farrell) Vol. 12, Part A, Academic Press, London, 1992, pp. 1-73.

3) G. H. Satchell: Circulation in Fishes, Cambridge University Press, Cambridge, England, 1971, pp. 31-38.

4) A. P. Farrell, J. A. Johansen, and M. S. Graham: The role of the pericardium in cardiac performance of the trout (Salmo gairdneri). Physiol. Zool., 61, 213-221 (1988).

5) A. P. Farrell, P. S. Davie, C. E. Franklin, J. A. Johansen, and R. W. Brill: Cardiac physiology in tunas. I. In vitro perfused heart preparations from yellowfin and skipjack tunas. Can. J. Zool., 70, $1200-1210$ (1992).

6) C. E. Franklin and P. S. Davie: The role of the pericardium in cardiac function in the dogfish, Squalus acanthias. J. Fish Biol., 43, 213-219 (1993).

7) A. P. Farrell: A review of cardiac performance in the teleost heart: intrinsic and humoral regulation. Can. J. Zool., 62, 523-536 (1984).

8) A. P. Farrell, S. Wood, T. Hart, and W. R. Driedzic: Myocardial oxygen consumption in the sea raven, Hemitripterus americanus: The effects of volume loading, pressure loading and progressive hypoxia. $J$. exp. Biol., 117, 237-250 (1985).

9) C. E. Franklin and P.S. Davie: The pericardium facilitates pressure work in the eel heart. J. Fish Biol., 39, 559-564 (1991).

10) R. M. Santer: Morphology and innervation of the fish heart. $A d v$. Anat. Embryology Cell Biology, 89, 1-102 (1985).

11) A. P. Farrell, K. MacLeod, and W. R. Driedzic: The effects of preload, after load, and epinephrine on cardiac performance in the sea raven, Hemitripterus americanus. Can. J. Zool., 60, 3165-3171 (1982).

12) P. V. Ngan, K. Yamamori, I. Hanyu, and T. Hibiya: Measurement of blood pressure of carp. Japan. Ichthyol., 21, 1-8 (1974).

13) C. E. Franklin and P. S. Davie: Dimensional analysis of the ventricle of an in situ perfused trout heart using echocardiography. $J$. exp. Biol., 166, 47-60 (1992).

14) J. H. Licht and W. S. Harris: The structure, composition and elastic properties of the teleost bulbus arteriosus in the carp, Cyprinus carpio. Comp. Biochem. Physiol., 46A, 699-708 (1973).

15) D. J. Randall: The circulatory system, in "Fish Physiology" (ed. by W. S. Hoar and D. J. Randall), Vol. 4, Academic Press, New York, 1970, pp. 132-172. 